\title{
Management of Internal Root Resorption with Bioceramic Material on Permanent Tooth-A Case Report
}

\author{
Indrajit Biswas ${ }^{1}$, Saikat Chatterjee ${ }^{1}$, Niladri Maiti ${ }^{2 *}$ and Paromita Mazumdar $^{3}$ \\ ${ }^{1}$ Post Graduate Trainee, Department of Conservative Dentistry \& Endodontics, Institute of Dental sciences \& Research, India
}

${ }^{2}$ Senior Lecturer, Department of Conservative Dentistry \& Endodontics, Institute of Dental sciences \& Research, India

${ }^{3}$ Professor and HOD, Department of Conservative Dentistry \& Endodontics, Institute of Dental sciences \& Research, India

*Corresponding author: Niladri Maiti, Senior Lecturer, Department of Conservative Dentistry \& Endodontics, Institute of Dental sciences \& Research, India

\begin{abstract}
Internal root resorption (IRR) is a category of pulp disease characterized by the loss of dentine as a result of the action of clastic cells stimulated by pulpal inflammation. The objective of this case report was to account for the diagnosis and management of an internal root resorption without perforation. The patient, a 26-year-old male, came to Guru Nanak Institute of Dental Sciences and Research, West Bengal, without having symptoms in the tooth. Endodontic treatment was performed using the following methods: irrigation of the root canal with $2.5 \%$ of sodium hypochlorite, then calcium hydroxide (CH) was applied as intracanal medicament for one month. Complete instrumentation was done with Hyflex One File (Coltene) and obturation with corresponding guta-percha and Roeko Guttaflow Bio seal sealer (Coltene). The patient was checked after one week and then after six months. He did not have any symptoms and IOPA radiograph did not show any further progression of the lesion.
\end{abstract}

Keywords: Internal Root Resorption; Calcium Hydroxide (CH); Sodium Hypochlorite; MTA

\section{Introduction}

The Glossary of the American Association of Endodontists defines internal root resorption (IRR) as a condition associated with a physiological or pathological process that results in the loss of dentin, cement and bone [1]. Most teeth with internal root resorption are symptom free and are first clinically recognized through routine radiographs. However, when resorption actively progresses, the tooth is only partially vital and may present typical symptoms of pulpitis. Bell (1830) first reported about IRR. Mummery (1920) called it "pink tooth of Mummery" due to the presence of pink discoloration on the crown [2]. This condition, although rare, is more frequent in the male population. The IRR is more common in the presence of a periapical lesion. Its prevalence was estimated between $0.01 \%$ and $1 \%$ depending on the inflammatory condition of the pulp [3]. The IRR could be caused by several stimuli: trauma, chronic inflammation of pulp/periodontal ligament, heat created by the friction of drills during the preparation of cavities, cracked tooth syndrome, tooth reimplantation and orthodontic treatment [4]. There have also been reported cases of internal reabsorption caused by Herpes Zoster virus [5]. The IRR is caused by inflammatory stimuli which produce an alteration of the odontoclast inhibitory mechanism resulting in an alteration of the pre-dentine layer. The vascular change in the pulp produces hyperemia increasing oxygen tension and causing an acidic $\mathrm{pH}$ level that attracts multinucleated cells, odontoclasts and dentin clasts. Dominance of inhibitory substances such as OPG (osteoprotegerin) as activators of RANKL (receptor activator of factor kappa B ligand) followed by swelling, results in the rupture of protective coatings allowing the invasion of odontoclasts and initiating resorptive patterns. Connective, post-resorptive activity tissue transforms into metaplastic granulation tissue [6]. Generally, IRR detection is done by X-rays, however, the use of cone beams computed tomography (CBCT) has been reported to be highly useful for diagnosis in endodontics, since it shows the lesion in detail and includes 
information about adjacent anatomy, which X-rays does not provide [7]. The periapical radiography is limited because it provides a twodimensional image [8], whereas diagnosis by CBCT shows images in all their dimensions through tomographic slices, without image overlay [9]. Also, diagnosis by CBCT may improve the accuracy and efficiency in the prognosis of the tooth [10]. Therapeutically, the biomaterial employed can influence the prognosis of the nonsurgical endodontic treatment done for extensive internal root resorption [11]. MTA is most commonly used in these cases because of its sealing ability, biocompatibility and potential induction of osteogenesis and cement genesis and it can be used in a humid environment [12]. Another study using an experimental immature tooth model, demonstrated that the MTA also increased the fracture resistance of bovine incisors when submitted to different reinforcement treatments Recently bioceramics are widely used in endodontics. Roeko Guttaflow Bio seal (COLTENE) is a bioceramic endodontic sealer which claims to avoid shrinkage upon setting as it has Zirconium oxide is used as the radiopacifier, and the material is claimed to be aluminum-free, non-soluble and does not shrink during setting. It gives advantage of flow of material as well as sealing ability which better bond with the corresponding gutta percha used for obturation [13]. The purpose of this case report is to describe the diagnosis and clinical management of an internal root resorption with bioceramic material.

\section{Case Report}

Male patient, 26 years old, treated at the post graduate department in Guru Nanak Institute of Dental Sciences and Research. The patient reported no pain at the time of appointment the chief complaint was discoloration of the front tooth which was traumatized 5 year back. Vitality tests using Endo-Ice (Coltene, Switzerland) were performed in [11]; the tooth gave negative response. The patient did not present tooth mobility and periodontal pockets. IOPA radiograph of the affected tooth\#11 showed an oval enlargement (ballooning out) of the root canal space (Figure 1). The pulp chamber and canal cannot be followed throughout the lesion. Radiograph performed at different angulation to confirm the resorptive lacunae is a continuation of the distorted border of the root canal. Endodontic treatment was suggested; therefore, isolation protocol was performed to make the cavity opening later (Figure 2). Working length of the tooth was determined by IOPA radiograph using \#15K file (Figure 3) and the result was confirmed with apex locator Canal Pro (COLTENE). After removing the pulp tissue properly chemical-mechanical instrumentation was performed with Hyflex One File (COLTENE) and irrigation was done with $1 \mathrm{ml}$ of $2.5 \%$ of sodium hypochlorite between each time instrumentation with 30 -gauge side vented needle. This was followed by irrigation with normal saline to remove any remnants of hypochlorite, later canal was dried with absorbent points. Ca $(\mathrm{OH})_{2}$ dressing was given for 1 month and the medicament was changed weekly. After one month, temporary restoration was removed with [4] round diamond bur, canal was irrigated with
$5 \mathrm{~mL}$ of $2.5 \%$ sodium hypochlorite $(\mathrm{NaOCl})$ and $5 \mathrm{~mL}$ of $17 \%$ of ethylenediaminetetraacetic acid for removing the $\mathrm{Ca}(\mathrm{OH})$ dressing and then the canal was flushed with normal saline and dried.

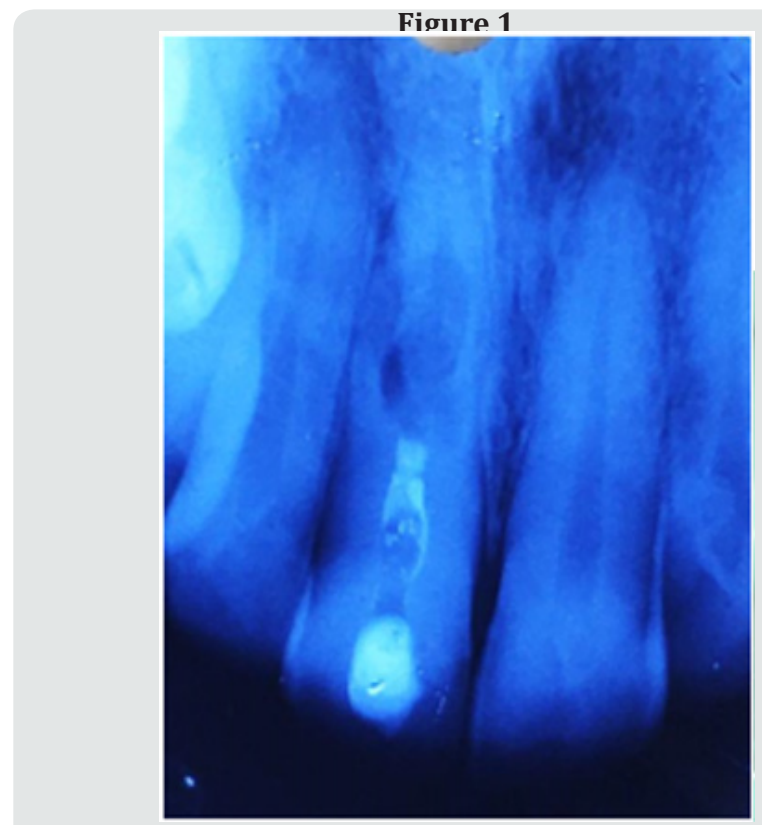

Figure 1.

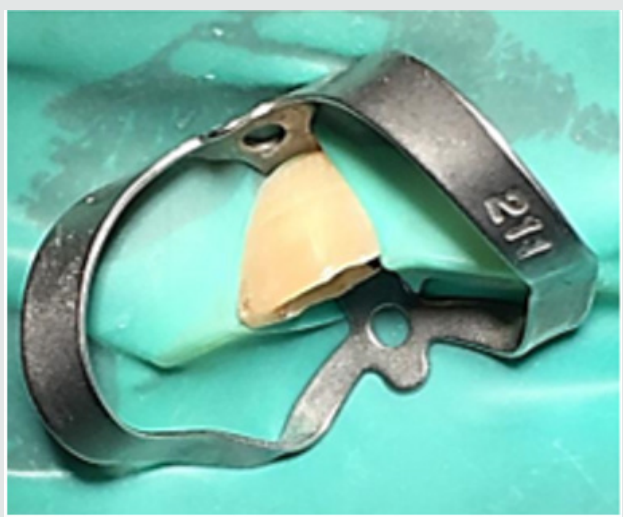

Figure 2.

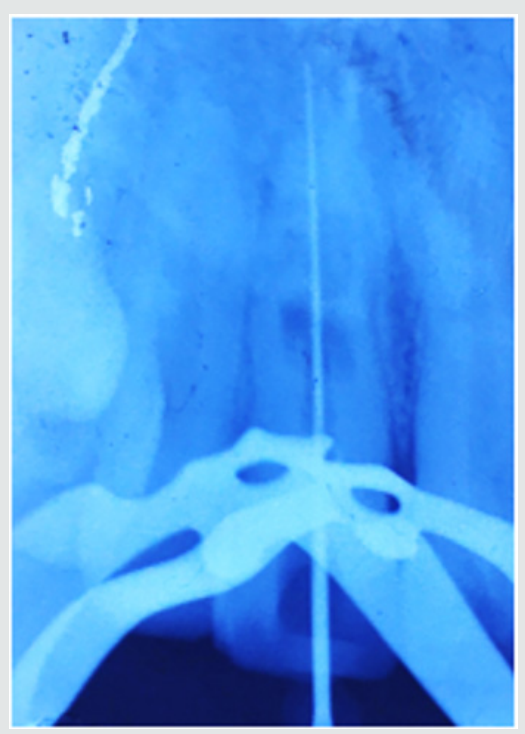

Figure 3. 


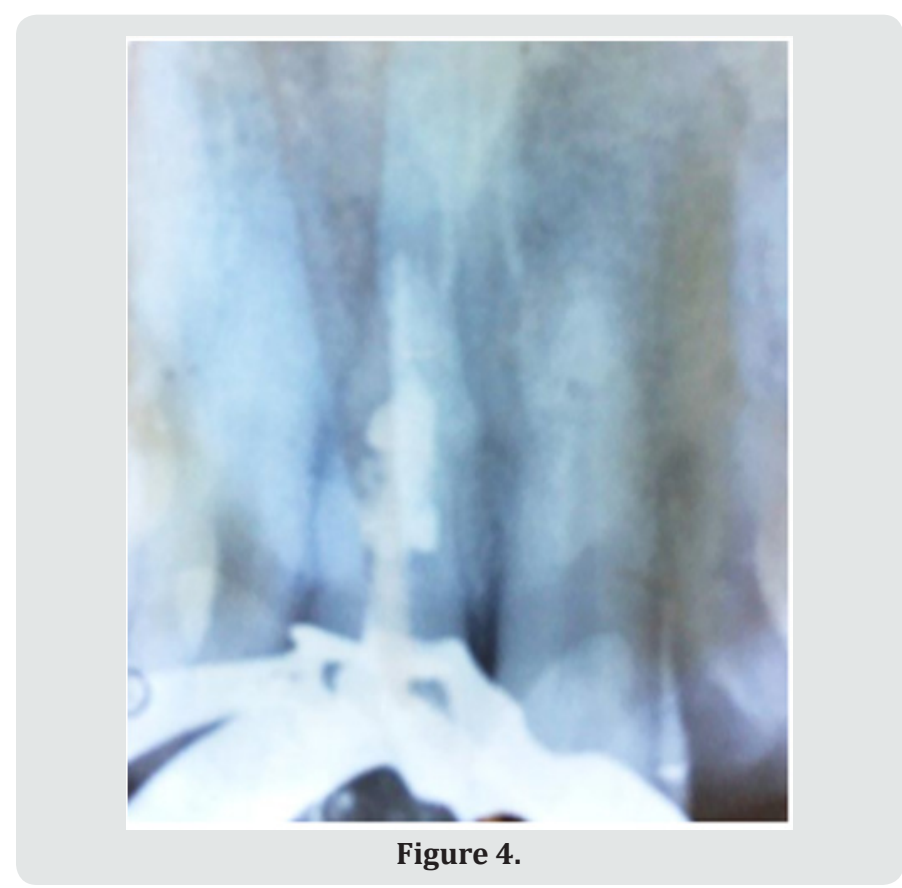

After removing the medication, obturation was done with Hyflex corresponding Gutta Percha and the remaining pulp chamber was obturated with Guttaflow Bio seal sealer (Figure 4). Access cavity restoration was done with light cure composite resin. The patient

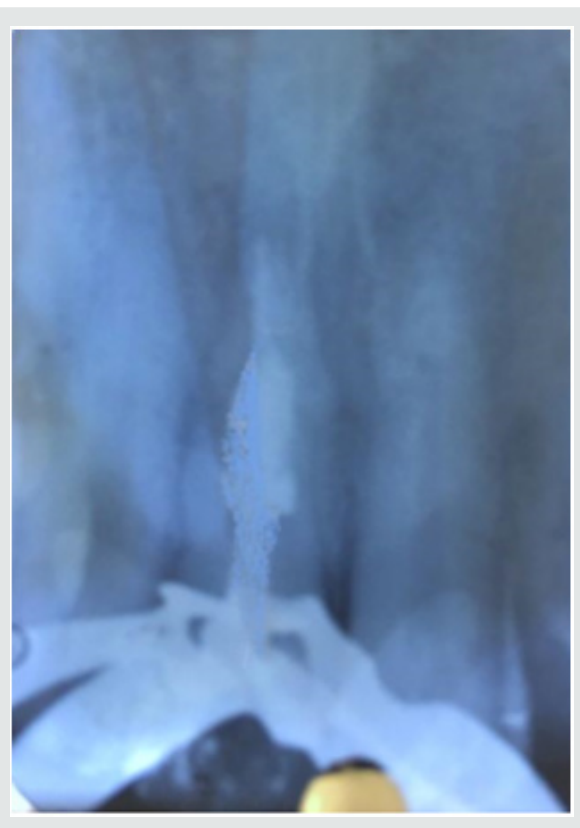

Figure 5.

was recalled after 6 and 12 months (Figure 5, 6) for clinical and radiographic follow up. Clinical examination of tooth was functional without sensitivity to percussion or palpation [11].

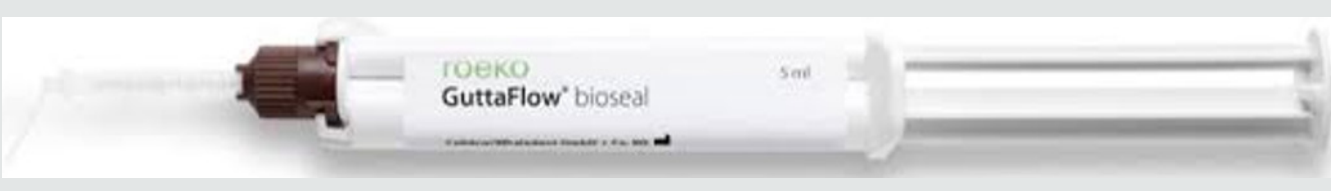

Figure 6.

\section{Discussion}

There is always a dilemma of whether to treat a tooth with a questionable prognosis endodontically or extract it and subsequently place an implant. Bell first reported a case on internal resorption in 1830. Since then there have been numerous reports in the literature [14]. Two types of internal root resorption are generally described: the internal root canal inflammatory resorption and the internal root canal replacement resorption. In the inflammatory resorption, the resorptive process of the intraradicular dentin progresses without adjunctive deposition of hard tissues adjacent to the resorptive sites. The phenomenon is associated with the presence of granulation tissues in the resorbed area and identifiable with routine radiographs as are radiolucent zone centered on the root canal. In the replacement resorption, the resorptive activity cause defects in the dentin adjacent to the root canal, with concomitant deposition of bone like tissue in some regions of the defect. It results in an irregular enlargement of the pulp space with partially or fully obliterated area of the pulp chamber. Internal resorption is the result of an inflamed pulp and the clastic precursor cells recruiting through the blood vessels. Treatment of internal resorption is quite predictable as it is easy to control the process of internal root resorption via severing the blood supply to the resorbing tissues with conventional root canal therapy. Intraoral X-ray of IRR is characterized by the radiographic appearance of an oval shape enlargement within the pulp chamber or the root canal. However, the early diagnosis of the IRR is difficult by examination of a conventional X-ray. If IRR is suspected, several shots under different angles of incidence are recommended. In the treatment of internal resorption, the use of calcium hydroxide also has two other important goals: to control bleeding, and to necrotize residual pulp tissue and to make the necrotic tissue more soluble to sodium hypochlorite. Because of the limited access by instruments to all areas of the resorption cavity, chemical means are needed to completely clean the canal. Studies on the effectiveness of sodium hypochlorite and calcium hydroxide to remove the resorptive and other tissues from the root canal indicate that they have an additive or even synergistic effect [15]. In cases where the resorption has not perforated, it is usually enough to use calcium hydroxide paste in the canal once from 1 to 2 weeks. This allows removal of the residual tissue at the next appointment by irrigation and instrumentation. In our treatment protocol, we choose Guttaflow Bio seal (COLTENE) sealer due to its versatile property of Bioceramic component \& gutta-percha 
particles. Upon contact with fluids, this material provides natural repair constituents, such as silicates and calcium, which contribute to the activation of biochemical processes, providing additional support to the root canal regeneration. A novel material for root canal filling that combines gutta-percha in a powder form with a particle size of less than $30 \mu \mathrm{m}$ and a sealer. The sealer has also showed least cytotoxicity as well as inflammatory reaction [15].

\section{Conclusion}

It is puzzling in diagnosing and treating a root resorption case, therefore a suitable management is perilous. Thorough investigations and discussion are required for the management especially when the prognosis of the tooth is poor upon consultation. Absence of periapical lesion and no signs and symptoms at the 12-months review provided a favorable outcome to once a tooth of hopeless prognosis.

\section{References}

1. Eleazer P, Glickman G, McClanahan S, Webb T, Jusrman B (2012) Glossary of Endodontic Terms. Editorial AAE. Chicago.

2. Mummery JH (1920) The pathology of "pink-spots" on teeth. Br Dent J 41: 301-311.

3. Nilsson E, Bonte E, Bayet F, Lasfargues JJ (2013) Management of internal root resorption on permanent teeth. Int J Dent, pp. 929486.

4. Patel S, Ricucci D, Durak C, Tay F (2010) Internal root resorption: a review. J Endod 36(7): 1107-1121

5. Talebzadeb B, Rahimi S, Abdollabi A, Nouroloyuni A, Asghari V (2015) Varicella Zoster virus and internal root resorption: A case report. J Endod 41(1): 1-7.
6. Thomas P, Krishna Pillai R, Pushparajan Ramakrishnan B, Palani J (2014) An insight into internal resorption. ISRN Dent, pp. 759326.

7. Venskutonis T, Plotino G, Juodzbalyz G, Mickeviciene L (2014) The importance of cone-beam computed tomography in the management of endodontic problems: A review of the literature. J Endod 40(12): 18951901.

8. Perlea P, Nistor C, Iliescu M, Iliescu A (2015) The use of cone beams computed tomography in the diagnosis and management of internal root resorption associated with chronic apical periodontitis: A case report. Rom J Morphol Embryol 56(1): 223-227.

9. Kamburoglu K, Kursun S (2010) A Comparison of the diagnostic accuracy of CBCT images of different voxel resolutions used to detect simulated small internal resorption cavities. Int Endod J 43(9): 798-807.

10. Silveira P, Fontana M, Oliveira M, Montagner F (2014) CBCT-based volume of simulated root resorption - influence of FOV and voxel size. Int Endod J 47(1): 1-7.

11. Torabinejad M, Chivian N (1999) Clinical applications of mineral trioxide aggregate. J Endod 25: 197-205.

12. Economides N, Pantelidou O, Kokkas A, Tziafas D (2003) Short-term periradicular tissue response to mineral trioxide aggregate (MTA) as root-end filling material. Int Endod J 36: 44-48.

13. Loushine BA, Bryan TE, Looney SW, Gillen BM, Loushine RJ, et al. (2011) Setting peroperties and cytotoxicity evaluation of a premixed bioceramic root canal sealer. J Endod 37: 673-677. Bell T. Philadelphia: Carey and Lee Publishing; 1830. The anatomy, physiology, and disease of the teeth; pp. 171-172.

14. Metzler RS, Montgomery S (1989) Effectiveness of ultrasonics and calcium hydroxide for the debridement of human mandibular molars. J Endod 15: 373-378.

15. S Pereira, HP Cunha, B Oliveiros, JM Santos, D Sequeira, et al. Endodontic sealers in dentistry - in vitro and in vivo cytotoxicity studies Polymer science: research advances, practical applications and educational aspects. A. Méndez-Vilas; A. Solano (Eds.).

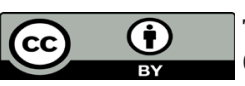

This work is licensed under Creative Commons Attribution 4.0 License

To Submit Your Article Click Here:

Submit Article

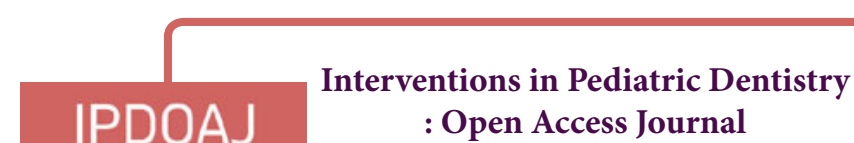

: Open Access Journal

Assets of Publishing with us

- Global archiving of articles

- Immediate, unrestricted online access

- Rigorous Peer Review Process

- Authors Retain Copyrights

- Unique DOI for all articles 